Research Paper

\title{
Necdin Overexpression Predicts Poor Prognosis in Pa- tients with Urothelial Carcinomas of the Upper Urinary Tract and Urinary Bladder
}

\author{
I-Wei Chang1,2, Yu-Hui Wang3,4, Wen-Jeng Wu5,6,7,8,9, Peir-In Liang10, Wei-Ming Li5,6,7,8,9, Bi-Wen Yeh5,6,7,8,9,
} Ting-Feng $\mathrm{Wu}^{11}$, Hong-Lin $\mathrm{He}^{1}$, Steven Kuan-Hua Huang12, ${ }^{1 凶}$, Chien-Feng $\mathrm{Li}^{4,11,13,14, \bowtie}$

1. Department of Pathology, E-DA Hospital, I-Shou University, Kaohsiung, Taiwan;

2. School of Medicine for International Students, I-Shou University, Kaohsiung, Taiwan;

3. Institute of Bioinformatics and Biosignal Transduction, National Cheng Kung University, Tainan, Taiwan;

4. Department of Pathology, Chi-Mei Medical Center, Tainan, Taiwan;

5. Graduate Institute of Medicine, College of Medicine, Kaohsiung Medical University, Kaohsiung, Taiwan;

6. Department of Urology, School of Medicine, College of Medicine, Kaohsiung Medical University, Kaohsiung, Taiwan;

7. Department of Urology, Kaohsiung Medical University Hospital, Kaohsiung, Taiwan;

8. Department of Urology, Kaohsiung Municipal Hsiao-Kang Hospital, Kaohsiung, Taiwan;

9. Center for Stem Cell Research, Kaohsiung Medical University, Kaohsiung, Taiwan;.

10. Department of Pathology, Kaohsiung Medical University Hospital, Kaohsiung Medical University, Kaohsiung, Taiwan;

11. Department of Biotechnology, Southern Taiwan University of Science and Technology, Tainan, Taiwan;

12. Department of Urology, Chi Mei Medical Center;

13. Graduate Institute of Medicine, College of Medicine, Kaohsiung Medical University, Kaohsiung, Taiwan;

14. National Institute of Cancer Research, National Health Research Institutes, Tainan, Taiwan.

$\square$ Corresponding authors: Chien-Feng Li, M.D., PhD., Department of Pathology, Chi Mei Medical Center, Tainan 701, Taiwan., E-mail: angelo.p@yahoo.com.tw, or Steven Kuan-Hua Huang., M.D., Ph.D., Department of Urology, Chi Mei Medical Center, Tainan 701, Taiwan., E-mail: skhsteven@gmail.com

( ) Ivyspring International Publisher. Reproduction is permitted for personal, noncommercial use, provided that the article is in whole, unmodified, and properly cited. See http://ivyspring.com/terms for terms and conditions.

Received: 2015.08.23; Accepted: 2015.10.28; Published: 2016.01.10

\begin{abstract}
Background and Aims: Oncogenesis is a multistep process, resulting from the accumulations of multiple mutations. Of these mutations, self-sufficiency in growth signals, i.e., disruption of cell growth regulation, is the first episode. Nonetheless, the genes associated with cell growth dysregulation have seldom been systematically evaluated in either urothelial carcinomas of upper urinary tract (UTUC) or urothelial carcinomas of urinary baldder (UBUC). By data mining a published transcriptomic dataset of UBUCs (GSE31684), we identified the NDN gene as one of the most significant of those associated with the regulation of cell growth and found this gene is associated with advanced tumor status and metastatic disease (GO:0001558). Accordingly, we analyzed NDN transcript and protein expression with their clinicopathological significance.

Materials and Methods: We used real time RT-PCR to detect NDN transcript levels in 27 UTUCs and 27 UBUCs, respectively. Immunohistochemical study was performed to determine NDN protein (a.k.a. Necdin) expression evaluated by H-score method in 340 UTUCs and 295 UBUCs. NDN expression was further correlated with clinicopathological features and disease-specific survival (DSS) and metastasis-free survival (MeFS).

Results: NDN transcriptional level was significantly higher in UCs of both sites with stepwise more advanced pT statuses. Through immunohistochemistry, we found NDN protein expression was significantly associated with adverse clinicopathological parameters, e.g., advanced PT status, nodal metastasis, high grade histological patterns, and frequent mitotses (all $P<0.05$ ). In univariate analysis, NDN overexpression not only predicted worse DSS and MeFS in both the UTUC and UBUC groups, it also served as an independent prognostic factor for DSS and MeFS in multivariate analysis (all $P<0.05$ ).

Conclusions: NDN may play an important role in tumor progression in UC and could serve as a prognostic biomarker and a potential novel therapeutic target in UC.
\end{abstract}

Key words: NDN gene, Necdin, Urothelial carcinoma, Prognosis. 


\section{Introduction}

Urothelial carcinoma (UC) is the most prevalent histological type of malignancy throughout the urinary tract, from the upper urinary tract (UT) to the urinary bladder (UB) [1]. The former consists of the renal pelvis and the ureter. In contrast to urothelial carcinoma of the urinary bladder (UBUC), which is the seventh most common cancer in the United States [2], urothelial carcinoma of the upper urinary tract (UTUC) is much uncommon and accounts for only $5 \%$ to $10 \%$ of all UCs [3]. Nevertheless, the incidence of UTUC in Taiwan is unusually high, especially in southern Taiwan and areas of endemic "Black-foot disease" [4-6]. Arsenic-contaminated drinking water may contribute to the prevalence of UTUC in Taiwan [6]. Etiologically, all UCs, regardless of anatomical location, are attributed to identical carcinogens, such as cigarette smoking, and aromatic amines, e.g. benzidine, $\beta$-naphtylanine [7-9]. However, certain populations are particularly predisposed to UTUC. For instance, patients with analgesic nephropathy [10], Chinese herb nephropathy [11, 12], and Balkans nephropathy $[11,13]$ are more susceptible to UTUC than UBUC. In spite of the fact that UTUCs usually have higher stage and grade than UBUCs, their clinical behavior is similar after balancing the stages and grades [14]. In addition, the previous study revealed that gene expression profiles of both UBUCs and UTUCs are much alike [15]. These findings indicate that carcinogensis of UCs from both anatomical locations may participate in a common molecular pathway.

Cancer is essentially a disease of regulation of cell growth; genes that regulate cell growth must be altered in order to transform normal cells into cancer cells [16]. Oncogenesis is a multistep process, resulting from the accumulations of multiple mutations. Of these mutations, self-sufficiency in growth signals, i.e., disruption of cell growth regulation is the first episode [17]. Nonetheless, the genes associated with cell growth dysregulation have seldom been systematically evaluated in either UTUC or UBUC. By data mining documented transcript expression profiles (GSE31684) in the Gene Expression Omnibus (GEO, National Center for Biotechnology Information (NCBI), Bethesda, MD, USA) with a special focus on growth regulation (GO:0001558), we found that transcription of the NDN gene was significantly upregulated from early tumor development and associated stepwise with tumor progression. This evidence suggests that the NDN gene plays an important role in tumorigenesis and its progression.

The NDN gene encodes Necdin protein, a member of the melanoma-associated antigen gene (MAGE) family [18] that was first identified in neu- rally differentiated mouse stem cells of P19 embryonal carcinoma cell lines treated with retinoic acid [19]. Necdin was originally recognized as a suppressor of cell proliferation in postmitotic neurons, leading the differentiated neurons into permanent withdrawal from the cell cycle due to constitutive and lifelong expression of Necdin [20]. Moreover, NDN transcripts and their encoded proteins showed downregulation or low expression in previous UBUC cell lines and human UBUC tissue studies [21]. Hence, we conducted this study to elucidate the expression of Necdin protein and NDN mRNA in UCs from both anatomical sites, as well as their association with clinicopathological parameters and clinical outcomes.

\section{Materials and Methods}

\section{Data mining the GEO to identify the most al- tered transcripts in UCs}

We performed data mining of the GEO of NCBI, identifying dataset GSE31684 (http:/ / www.ncbi.nlm. nih.gov/geo/query/acc.cgi?acc=GSE31684) in order to analyze radical cystectomy specimens from 93 patients with UBUC using the Affymetrix GeneChip Human Genome U133 Plus 2.0 Array. To analyze all probe sets, we used Nexus Expression 3 statistical software (BioDiscovery, El Segundo, CA, USA) without preselection or filtering. Under supervision, our comparative analysis examined the statistical significance of differentially expressed transcripts on the basis of primary tumor status (pT) and the development of metastatic events. We performed functional profiling using transcriptomes of high-stage UCs (pT2-pT4) with metastases and low-stage UCs (pTa-pT1) devoid of metastasis, focusing on those related to the regulation of cell growth (GO:0001558). We further analyzed survival patterns by dichotomizing all cases into high-expression and low-expression clusters for computing the prognostic significance of the selected genes.

\section{Patients and tumor specimens}

The Institutional Review Board of Chi Mei Medical Center approved this study (IRB971006). For immunohistochemical study and survival analysis, we enrolled 635 consecutive cases diagnosed as conventional UC between 1996 and 2004, from the archives of the Department of Pathology, Chi-Mei Medical Center. Of these cases, 340 tumors originated from the UT and 295 arose from the UB. Other histological classifications as well as variants of UC were excluded. The criteria for clinicopathological evaluation were essentially identical to those in our previous work [22]. Detailed information is provided in the online supplementary material. 


\section{Transcriptional levels of the NDN gene}

The materials for genetic examination were gathered from macrodissection of fresh tumor tissue. For quantification of NDN mRNA expression, we extracted total RNAs, quantified them, and submitted them for reverse-transcription from 27 UTUCs and 27 UBUCs (both were composed of 9 cases of pTa; 9 pT1; 9 pT2-4), respectively. Using pre-designed TaqMan assay reagents (Applied Biosystems, Waltham, MA, USA), we measured mRNA abundance of NDN (Hs00267349_s1) with the ABI StepOnePlus ${ }^{\mathrm{TM}}$ System, as previously described [23]. We calculated the fold expression of $N D N$ relative to normal urothelium by comparative $\mathrm{Ct}$ method, after normalization to POLR2A (Hs01108291_m1) as the internal control.

\section{Immunohistochemical staining and scoring of NDN}

Tissue sections underwent standard procedures for deparaffinization, rehydration and antigen retrieval. Afterwards, the sections were incubated with a primary antibody targeting NDN (TA506975, 1:150; OriGene, Rockville, MD, USA) for an hour. Normal brain tissue with or without incubation of primary antibody were run in parallel as positive and negative control, respectively. We scored NDN immunoreactivity based on the combination of the percentage and intensity of positivity of the immunostain in tumoral nuclei in order to generate an H-score, which was calculated using the following equation: $\mathrm{H}$-score $=\Sigma P_{i}(i+1)$, where $i$ is the intensity of stained tumor cells $(0-3+)$, and $P i$ is the percentage of stained tumor cells for each intensity varying from $0 \%$ to $100 \%$. This formula produced a score range from $100-400$, where 100 indicated that $100 \%$ of tumor cells were negative and 400 indicated $100 \%$ of tumor cells were strongly stained $(3+)[24,25]$.

\section{Statistical analysis}

We performed statistics using SPSS V.14.0 software (SPSS Inc., Chicago, IL, USA). The median $\mathrm{H}$-score of NDN immunoreactivity was used as the cut-off to dichotomize the study cohort, separating cases into high expression and low expression groups. We used Pearson's $\chi^{2}$ test to compare NDN expression status and various categorical clinicopathological parameters. Mann-Whitney U test was used to compare NDN expression and numerical ones, i.e., mitotic rate. The end points analyzed were disease-specific survival (DSS) and metastasis-free survival (MeFS), calculated from the date of tumor resection to the date the event developed. Patients lost to follow-up were censored on the latest follow-up date. We performed univariate survival analyses using Kaplan-Meier plots and compared them by log-rank test. Those parame- ters with univariate $P<0.1$ were enrolled into multivariate tests using Cox proportional hazards regression. For all analyses, we used two-sided tests of significance, with $P<0.05$ considered statistically significant.

\section{Results}

\section{NDN is a significant differentially upregulated transcript linked with regulation of cell growth in UBUCs}

From the transcriptomic profiling of 93 UBUC cases (GSE31684), which contains 78 high-stage (T2-T4) and 15 low-stage (Ta-T1) cases, 28 with metastatic disease and 49 without metastasis, we identified six probes covering two transcripts associated with regulation of cell growth (GO:0001558) (Figure 1). As shown in Table 1, both transcripts, i.e., IGFBP5 and $N D N$, were significantly upregulated with a $\log 2$ ratio of 0.337 to 2.6399 -fold and 0.7821 -fold upregulation, respectively, comparing high-stage to low-stage (all $P<0.005)$. IGFBP5 and NDN upregulation also showed statistically significant association with metastatic disease in all probes (all $P \leqq 0.0001$ ). Comparing high-expression $(n=37)$ to low-expression $(n=56)$ clusters, high expression levels of NDN transcripts significantly predicted worse disease-specific survival (Figure S1, $P=0.0059$ ). We had investigated IGFBP5 in a previous study [26]; however, NDN has not previously been systematically studied in UCs. Hence, we further characterized the endogenous expression levels and clinical significance of both NDN transcript and its protein in UC.

\section{Higher NDN mRNA transcriptional levels in UBUCs and UTUCs with advanced $\mathrm{pT}$ stage}

In the examined 27 UBUCs and 27 UTUCs, NDN transcripts were significantly more abundant in tumors with stepwise more advanced $\mathrm{pT}$ status, from pTa to pT1 to pT2-4 (all $P<0.05)$, suggesting it plays a role in tumor progression (Figure 2).

\section{Clinicopathological findings on UTUCs and UBUCs}

Clinicopathological features of the patients with UTUCs and UBUCs are listed in Table 2. In the UTUC group, no obvious sex predilection was noted despite there being slightly more women $(n=182,53.5 \%)$. In contrast, the majority of patients with UBUC were male $(n=216,73.2 \%)$. For both types of UC, most patients' age at diagnosis was older than 65 years $(n=202,59.4 \%$ for UTUC and $n=174,59.0 \%$ for UBUC). In the UTUC group, synchronous multifocal tumors occurred in 62 patients (18.2\%); both the renal pelvis and ureter were involved in $49(14.4 \%)$ of these. In both UC groups, most tumors were classified as high 
histological grade $(n=284,83.5 \%$ for UTUC and $n=239$, $81 \%$ for UBUC). Advanced pT stages (pT2-T4) were seen in $46.8 \%(n=159)$ and $41.7 \%(n=123)$ of patients with UTUCs and UBUCs, respectively. Nodal metastasis was detected in $8.2 \%(n=28)$ and $9.8 \%(n=29)$ of UTUC and UBUC patients, respectively. Vascular invasion was noted in $31.2 \%$ of UTUC $(n=106)$ and $16.6 \%$ of UBUC cases $(n=49)$; while perineurial invasion was observed in $5.6 \%$ of UTUC $(n=19)$ and $6.8 \%$ of UBUC cases $(n=20)$. In addition, about half of the tumors showed ten or more mitoses per ten high power fields $(n=167,49.1 \%$ for UTUC and $n=156$, $52.9 \%$ for UBUC).

\section{Correlations between immunoreactivity of NDN and clinicopathological parameters in UTUCs and UBUCs}

NDN showed variable nuclear expression in UCs from both sites. The median $\mathrm{H}$-score for each group was 105 and 370 for the UTUCs and UBUCs, respectively. As Table 2 demonstrates, after dichotomizing tumors into low and high NDN expression, increased NDN expression in UC of both anatomical sites was significantly associated with stepwise increases of pT status (Figure 3, UTUC, $P=0.003$; UBUC, $P<0.001$ ), lymph node metastasis (UTUC, $P=0.002$; UBUC, $P=0.012)$, high grade histological patterns (UTUC, $P=0.019$; UBUC, $P=0.003$ ) and higher mitotic rate (UTUC, $P=0.004 ; \mathrm{UBUC}, P=0.005$ ). Increased NDN expression was significantly associated with vascular invasion and perineural invasion only in the UBUC group ( $P=0.008$ and 0.001 , respectively).

\section{Survival analysis for UTUC and UBUC pa- tients}

The univariate and multivariate analyses of relationships between clinical outcomes and miscellaneous clinicopathological parameters in both UTUC and UBUC patients are illustrated in Tables 3-4. In multivariate analysis, multifocality $(P=0.007)$, nodal metastasis $(P<0.001)$, high histological grade $(P=0.007)$ and perineurial invasion $(P=0.001)$ are independent prognostic factors for poor DSS in the UTUC group. Similarly, inferior MeFS was significantly associated with multifocality $(P=0.002)$, nodal metastasis $(P=0.001)$, high histological grade $(P=0.030)$, vascular invasion $(P<0.001)$ and perineurial invasion $(P=0.014)$ in patients with UTUCs. In UTUCs, advanced pT status was significantly associated with worse DSS and MeFS in univariate $(P<0.0001)$ but not in multivariate analyses. Tumor location and vascular invasion in UTUC group correlated with poorer patient DSS in univariate analysis only $(P=0.0079$ and $P<0.0001$, respectively).

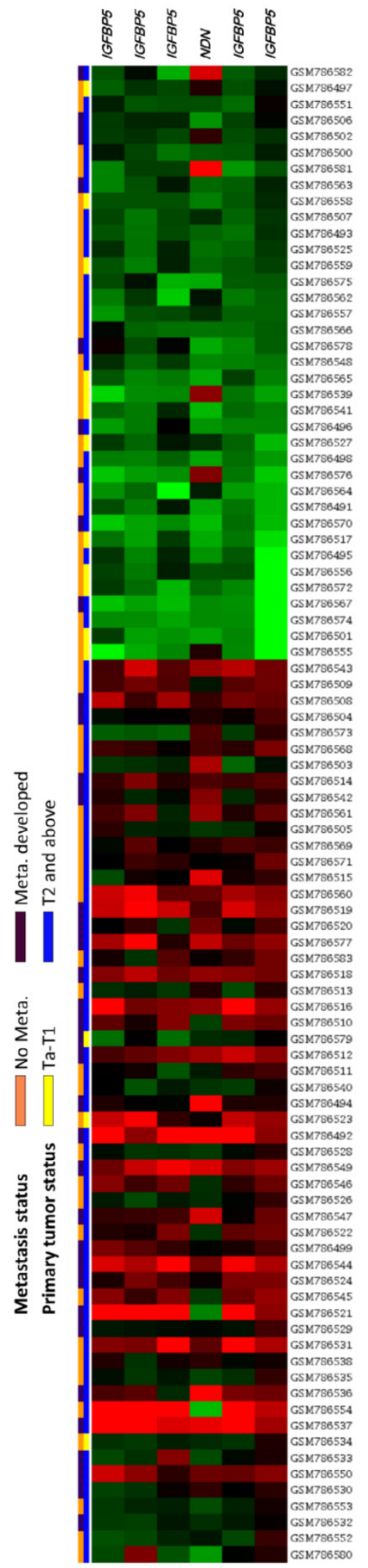

Figure 1. Analysis of gene expression in urothelial carcinoma using a published transcriptomic dataset (GSE31684). Clustering analysis of genes focused on the regulation of cell growth (GO:0001558) revealed NDN is one of the most significantly upregulated genes associated with increments of $\mathrm{PT}$ status and metastatic disease. Tissue specimens from tumors with different $\mathrm{pT}$ statuses are indicated on top of the heatmap, and expression levels of upregulated and downregulated genes are represented as a spectrum of brightness or red and green, respectively. Those with unaltered mRNA transcriptional levels are coded black. 
In the UBUC group, multivariate analysis revealed advanced $\mathrm{pT}$ status and higher mitotic rate were significantly associated with both dismal DDS and MeFS (all $P<0.05)$. Lymph node metastasis was significantly associated with poor MeFS $(P=0.037)$ in multivariate analysis, as well. In UBUCs, high histological grade, and vascular and perineural invasion were significantly associated with both adverse DSS and MeFS in univariate analysis (all $P<0.005$ ), but not in multivariate analysis.

\section{Prognostic significance of NDN expression in UC}

As shown in Tables 3-4 and Figure 4, in univariate analysis, either the UTUC or UBUC group with NDN overexpression had significantly worse DSS and MeFS ( $P<0.005$ for all). Notably, in multivariate analysis, high NDN nuclear expression was still an independent prognosticator predicting more dismal DSS and MeFS for all UCs $(P<0.05$ for all).

Table 1. Summary of differentially expressed genes associated with regulation of cell growth (GO:0001558) and showed positive associations to cancer invasiveness and metastasis in the transcriptome of urothelial carcinoma of urinary bladder (GSE31684).

\begin{tabular}{|c|c|c|c|c|c|c|c|}
\hline \multirow[t]{2}{*}{ Probe } & \multicolumn{2}{|c|}{$\begin{array}{c}\text { Comparing } \mathrm{T} 2-4 \text { to } \\
\text { Ta-T1 }\end{array}$} & \multicolumn{2}{|c|}{$\begin{array}{l}\text { Comparing Meta. to } \\
\text { Non-Meta.\# }\end{array}$} & \multirow[t]{2}{*}{ Gene Symbol } & \multirow[t]{2}{*}{ Biological Process } & \multirow[t]{2}{*}{ Molecular Function } \\
\hline & log ratio & p-value & log ratio & p-value & & & \\
\hline 1554741_s_at & 0.4313 & $<0.0001$ & 0.3919 & $<0.0001$ & IGFBP5 & regulation of cell growth, signal transduction & $\begin{array}{l}\text { growth factor binding, insu- } \\
\text { lin-like growth factor binding }\end{array}$ \\
\hline 201666_at & 1.1435 & 0.0001 & 1.0825 & $<0.0001$ & IGFBP5 & regulation of cell growth, signal transduction & $\begin{array}{l}\text { growth factor binding, insu- } \\
\text { lin-like growth factor binding }\end{array}$ \\
\hline 205131_x_at & 0.337 & 0.0008 & 0.2968 & 0.0001 & IGFBP5 & regulation of cell growth, signal transduction & $\begin{array}{l}\text { growth factor binding, insu- } \\
\text { lin-like growth factor binding }\end{array}$ \\
\hline 205168_at & 0.7821 & 0.0044 & 1.0228 & $<0.0001$ & $N D N$ & $\begin{array}{l}\text { axon extension involved in development, axonal } \\
\text { fasciculation, axonogenesis, central nervous system } \\
\text { development, glial cell migration, negative regula- } \\
\text { tion of cell proliferation, nerve growth factor re- } \\
\text { ceptor signaling pathway, nervous system devel- } \\
\text { opment, neuron development, neuron migration, } \\
\text { regulation of cell growth, regulation of progression } \\
\text { through cell cycle, regulation of transcription; } \\
\text { DNA-dependent, respiratory gaseous exchange, } \\
\text { sensory perception of pain, transcription }\end{array}$ & $\begin{array}{l}\text { DNA binding, gamma-tubulin } \\
\text { binding, protein binding }\end{array}$ \\
\hline 205782_at & 0.8325 & 0.0003 & 0.8815 & $<0.0001$ & IGFBP5 & regulation of cell growth, signal transduction & $\begin{array}{l}\text { growth factor binding, insu- } \\
\text { lin-like growth factor binding }\end{array}$ \\
\hline 207426_s_at & 2.6399 & $<0.0001$ & 1.4678 & $<0.0001$ & IGFBP5 & regulation of cell growth, signal transduction & $\begin{array}{l}\text { growth factor binding, insu- } \\
\text { lin-like growth factor binding }\end{array}$ \\
\hline
\end{tabular}

\#, Meta., distal metastasis developed during follow-up; Non-Meta.: no metastatic event developed.

Table 2. Correlations between NDN expression and other important clinicopathological parameters in urothelial carcinomas.

\begin{tabular}{|c|c|c|c|c|c|c|c|c|c|}
\hline \multirow[t]{3}{*}{ Parameter } & \multirow[t]{3}{*}{ Category } & \multicolumn{4}{|c|}{ Upper Urinary Tract Urothelial Carcinoma } & \multicolumn{4}{|c|}{ Urinary Bladder Urothelial Carcinoma } \\
\hline & & \multirow[t]{2}{*}{ Case No. $(\%)$} & \multicolumn{2}{|c|}{ NDN Expression } & \multirow[t]{2}{*}{ p-value } & \multirow[t]{2}{*}{ Case No. (\%) } & \multicolumn{2}{|c|}{ NDN Expression } & \multirow[t]{2}{*}{ p-value } \\
\hline & & & Low $(\%)$ & High (\%) & & & Low $(\%)$ & High $(\%)$ & \\
\hline \multirow[t]{2}{*}{ Gender } & Male & $158(46.5)$ & $86(54.4)$ & $72(45.6)$ & 0.128 & $216(73.2)$ & $109(50.5)$ & $107(49.5)$ & 0.719 \\
\hline & Female & $182(53.5)$ & $84(46.2)$ & $98(53.8)$ & & $79(26.8)$ & $38(48.1)$ & $41(51.9)$ & \\
\hline \multirow[t]{2}{*}{ Age (years) } & $<65$ & $138(40.6)$ & $70(50.7)$ & $68(49.3)$ & 0.825 & $121(41.0)$ & $59(48.8)$ & $62(51.2)$ & 0.759 \\
\hline & $\geq 65$ & $202(59.4)$ & $100(49.5)$ & $102(50.5)$ & & $174(59.0)$ & $88(50.6)$ & $86(49.4)$ & \\
\hline \multirow[t]{3}{*}{ Tumor location } & Renal pelvis & $141(41.5)$ & $71(50.4)$ & $70(49.6)$ & 0.685 & - & - & - & - \\
\hline & Ureter & $150(44.1)$ & $72(48.0)$ & $78(52.0)$ & & - & - & - & - \\
\hline & Renal pelvis \& ureter & $49(14.4)$ & $27(55.1)$ & $22(44.9)$ & & - & - & - & - \\
\hline \multirow[t]{2}{*}{ Multifocality } & Single & $278(81.8)$ & 138 (49.6) & $140(50.4)$ & 0.779 & - & - & - & - \\
\hline & Multifocal & $62(18.2)$ & $32(51.6)$ & $30(48.4)$ & & - & - & - & - \\
\hline \multirow[t]{3}{*}{ Primary tumor $(\mathrm{pT})$} & pTa & $89(26.2)$ & $56(62.9)$ & $33(37.1)$ & $0.003^{*}$ & $84(28.5)$ & $62(73.8)$ & $22(26.2)$ & $<0.001^{*}$ \\
\hline & pT1 & $92(27.0)$ & $49(53.3)$ & $43(46.7)$ & & $88(29.8)$ & $48(54.5)$ & $40(45.5)$ & \\
\hline & pT2-pT4 & $159(46.8)$ & $65(40.9)$ & $94(59.1)$ & & $123(41.7)$ & $37(30.0)$ & $86(70.0)$ & \\
\hline \multirow[t]{2}{*}{ Nodal metastasis } & Negative (pN0) & $312(91.8)$ & $164(52.6)$ & $148(47.4)$ & $0.002^{*}$ & $266(90.2)$ & $139(52.3)$ & 127 (47.7) & $0.012^{*}$ \\
\hline & Positive (pN1-pN3) & $28(8.2)$ & $6(21.4)$ & $22(78.6)$ & & $29(9.8)$ & $8(27.6)$ & $21(72.4)$ & \\
\hline \multirow[t]{2}{*}{ Histological grade } & Low grade & $56(16.5)$ & $36(64.3)$ & $20(35.7)$ & $0.019^{*}$ & $56(19.0)$ & $38(67.9)$ & $18(32.1)$ & $0.003^{*}$ \\
\hline & High grade & $284(83.5)$ & $134(47.2)$ & $150(52.8)$ & & $239(81.0)$ & $109(45.6)$ & $130(54.4)$ & \\
\hline \multirow[t]{2}{*}{ Vascular invasion } & Absent & $234(68.9)$ & $122(52.1)$ & $112(47.9)$ & 0.242 & $246(83.4)$ & $131(53.3)$ & $115(46.7)$ & $0.008^{*}$ \\
\hline & Present & $106(31.1)$ & $48(45.3)$ & $58(54.7)$ & & 49 (16.6) & $16(32.7)$ & $33(67.3)$ & \\
\hline \multirow[t]{2}{*}{ Perineural invasion } & Absent & $321(94.4)$ & $164(51.1)$ & 157 (48.9) & 0.098 & $275(93.2)$ & $144(52.4)$ & $131(47.6)$ & $0.001^{*}$ \\
\hline & Present & $19(5.6)$ & $6(31.6)$ & $13(68.4)$ & & $20(6.8)$ & $3(15.0)$ & $17(85.0)$ & \\
\hline $\begin{array}{l}\text { Mitotic rate (per } 10 \\
\text { high power fields)\# }\end{array}$ & & 340 & $9.66+/-7.315$ & $14.96+/-15.324$ & $0.004^{*}$ & 295 & $11.41+/-10.286$ & $17.38+/-16.469$ & $0.005^{*}$ \\
\hline
\end{tabular}


Table 3. Univariate log-rank and multivariate analyses for Disease-specific and Metastasis-free Survivals in upper urinary tract urothelial carcinoma.

\begin{tabular}{|c|c|c|c|c|c|c|c|c|c|c|c|c|}
\hline \multirow[t]{3}{*}{ Parameter } & \multirow[t]{3}{*}{ Category } & \multirow{3}{*}{$\begin{array}{l}\text { Case No. } \\
(\%)\end{array}$} & \multicolumn{5}{|c|}{ Disease-specific Survival } & \multicolumn{5}{|c|}{ Metastasis-free Survival } \\
\hline & & & \multicolumn{2}{|c|}{ Univariate analysis } & \multicolumn{3}{|c|}{ Multivariate analysis } & \multicolumn{2}{|c|}{ Univariate analysis } & \multicolumn{3}{|c|}{ Multivariate analysis } \\
\hline & & & $\begin{array}{l}\text { No. of event } \\
(\%)\end{array}$ & $\mathrm{p}$-value & R.R. & 95\% C.I. & p-value & $\begin{array}{l}\text { No. of event } \\
(\%)\end{array}$ & p-value & R.R. & 95\% C.I. & p-value \\
\hline \multirow[t]{2}{*}{ Gender } & Male & $158(46.5)$ & $28(17.7)$ & 0.8286 & - & - & - & $32(20.3)$ & 0.7904 & - & - & - \\
\hline & Female & $182(53.5)$ & $33(18.1)$ & & - & - & - & $38(20.9)$ & & - & - & - \\
\hline \multirow[t]{2}{*}{ Age (years) } & $<65$ & $138(40.6)$ & $26(18.8)$ & 0.9943 & - & - & - & $30(21.7)$ & 0.8470 & - & - & - \\
\hline & $\geq 65$ & $202(59.4)$ & $35(17.3)$ & & - & - & - & $40(19.8)$ & & - & - & - \\
\hline \multirow[t]{3}{*}{ Tumor side } & Right & $177(52.1)$ & 34 (19.2) & 0.7366 & - & - & - & $38(21.5)$ & 0.3074 & - & - & - \\
\hline & Left & $154(45.3)$ & $26(16.9)$ & & - & - & - & $32(20.8)$ & & - & - & - \\
\hline & Bilateral & $9(2.6)$ & $1(11.1)$ & & - & - & - & $0(0)$ & & - & - & - \\
\hline \multirow{3}{*}{$\begin{array}{l}\text { Tumor loca- } \\
\text { tion }\end{array}$} & Renal pelvis & 141 (41.5) & $24(17.0)$ & $0.0079^{*}$ & 1 & - & 0.840 & $31(22.0)$ & 0.0659 & - & - & - \\
\hline & Ureter & $150(44.1)$ & $22(14.7)$ & & 0.876 & $0.472-1.625$ & & $25(16.7)$ & & - & - & - \\
\hline & $\begin{array}{l}\text { Renal pelvis \& } \\
\text { ureter }\end{array}$ & 49 (14.4) & $15(30.6)$ & & 1.286 & $0.607-7.438$ & & $14(28.6)$ & & - & - & - \\
\hline \multirow[t]{2}{*}{ Multifocality } & Single & $278(81.8)$ & 48 (17.3) & $0.0026^{*}$ & 1 & - & $0.007^{*}$ & $52(18.7)$ & $0.0127^{*}$ & 1 & - & $0.002^{*}$ \\
\hline & Multifocal & $62(18.2)$ & $18(29.0)$ & & 2.821 & $1.321-6.024$ & & $18(29.0)$ & & 2.402 & $\begin{array}{l}1.381-4.4 \\
178\end{array}$ & \\
\hline \multirow{3}{*}{$\begin{array}{l}\text { Primary } \\
\text { tumor (pT) }\end{array}$} & pTa & $89(26.2)$ & $2(2.2)$ & $<0.0001^{*}$ & 1 & - & 0.071 & $4(4.5)$ & $<0.0001^{*}$ & 1 & - & 0.227 \\
\hline & pT1 & $92(27.0)$ & $9(9.8)$ & & 3.042 & $0.646-14.324$ & & $15(16.3)$ & & 2.344 & $\begin{array}{l}0.756-7.2 \\
67\end{array}$ & \\
\hline & pT2-pT4 & $159(46.8)$ & $50(31.4)$ & & 5.159 & $1.150-23.153$ & & $51(32.1)$ & & 2.497 & $\begin{array}{l}0.795-7.8 \\
46\end{array}$ & \\
\hline \multirow[t]{2}{*}{$\begin{array}{l}\text { Nodal me- } \\
\text { tastasis }\end{array}$} & $\begin{array}{l}\text { Negative } \\
\text { (pN0) }\end{array}$ & 312 (91.8) & $42(13.5)$ & $<0.0001^{*}$ & 1 & - & $<0.001^{*}$ & 55 (17.6) & $<0.0001^{*}$ & 1 & - & $0.001^{*}$ \\
\hline & $\begin{array}{l}\text { Positive } \\
\text { (pN1-pN3) }\end{array}$ & $28(8.2)$ & 19 (67.9) & & 5.071 & $2.753-9.340$ & & 15 (53.6) & & 2.888 & $\begin{array}{l}1.552-5.3 \\
72\end{array}$ & \\
\hline \multirow{2}{*}{$\begin{array}{l}\text { Histological } \\
\text { grade }\end{array}$} & Low grade & $56(16.5)$ & $4(7.1)$ & $0.0215^{*}$ & 1 & - & $0.007^{*}$ & $3(5.4)$ & $0.0027^{*}$ & 1 & - & $0.030^{*}$ \\
\hline & High grade & $284(83.5)$ & $57(20.0)$ & & 3.853 & $1.441-10.298$ & & 67 (23.6) & & 3.818 & $\begin{array}{l}1.139-12 . \\
792\end{array}$ & \\
\hline \multirow{2}{*}{$\begin{array}{l}\text { Vascular } \\
\text { invasion }\end{array}$} & Absent & $234(68.9)$ & $24(10.3)$ & $<0.0001^{*}$ & 1 & - & 0.059 & $26(11.1)$ & $<0.0001^{*}$ & 1 & - & $<0.001^{*}$ \\
\hline & Present & $106(31.1)$ & 37 (34.9) & & 1.774 & $0.978-3.218$ & & $44(41.5)$ & & 2.960 & $\begin{array}{l}1.625-5.3 \\
92\end{array}$ & \\
\hline \multirow{2}{*}{$\begin{array}{l}\text { Perineural } \\
\text { invasion }\end{array}$} & Absent & $321(94.4)$ & $50(15.6)$ & $<0.0001^{*}$ & 1 & - & $0.001^{*}$ & $61(19.0)$ & $<0.0001^{*}$ & 1 & - & $0.014^{*}$ \\
\hline & Present & $19(5.6)$ & $11(57.9)$ & & 3.463 & $1.661-7.222$ & & $9(47.4)$ & & 2.562 & $\begin{array}{l}1.208-5.4 \\
34\end{array}$ & \\
\hline \multirow{2}{*}{$\begin{array}{l}\text { Mitotic rate } \\
\text { (per } 10 \text { high } \\
\text { power fields) }\end{array}$} & $<10$ & $173(50.9)$ & 27 (15.6) & 0.167 & - & - & & $30(17.3)$ & 0.0823 & - & - & \\
\hline & $>=10$ & $167(49.1)$ & $34(20.4)$ & & - & - & & $40(24.0)$ & & - & - & \\
\hline \multirow{2}{*}{$\begin{array}{l}\text { NDN ex- } \\
\text { pression }\end{array}$} & Low & $170(50.0)$ & $17(10.0)$ & $0.0002^{*}$ & 1 & - & $0.032^{*}$ & $24(14.1)$ & $0.0027^{*}$ & 1 & - & $0.033^{*}$ \\
\hline & High & $170(50.0)$ & $44(25.9)$ & & 1.893 & $1.058-3.385$ & & $46(27.1)$ & & 1.731 & $\begin{array}{l}1.044-2.8 \\
69\end{array}$ & \\
\hline
\end{tabular}

* Statistically significant.

Table 4. Univariate log-rank and multivariate analyses for Disease-specific and Metastasis-free Survivals in urinary bladder urothelial carcinoma.

\begin{tabular}{|c|c|c|c|c|c|c|c|c|c|c|c|c|}
\hline \multirow[t]{3}{*}{ Parameter } & \multirow[t]{3}{*}{ Category } & \multirow{3}{*}{$\begin{array}{l}\text { Case No. } \\
(\%)\end{array}$} & \multicolumn{5}{|c|}{ Disease-specific Survival } & \multicolumn{5}{|c|}{ Metastasis-free Survival } \\
\hline & & & \multicolumn{2}{|c|}{ Univariate analysis } & \multicolumn{3}{|c|}{ Multivariate analysis } & \multicolumn{2}{|c|}{ Univariate analysis } & \multicolumn{3}{|c|}{ Multivariate analysis } \\
\hline & & & $\begin{array}{l}\text { No. of } \\
\text { event (\%) }\end{array}$ & p-value & R.R. & 95\% C.I. & p-value & $\begin{array}{l}\text { No. of } \\
\text { event (\%) }\end{array}$ & p-value & R.R. & 95\% C.I. & $\mathrm{p}$-value \\
\hline \multirow[t]{2}{*}{ Gender } & Male & $216(73.2)$ & $41(19.0)$ & 0.4446 & - & - & - & $60(27.8)$ & 0.2720 & - & - & - \\
\hline & Female & $79(26.8)$ & $11(13.9)$ & & - & - & - & $16(20.3)$ & & - & - & - \\
\hline \multirow[t]{2}{*}{ Age (years) } & $<65$ & $121(41.0)$ & $17(14.0)$ & 0.1136 & - & - & - & $31(25.6)$ & 0.6875 & - & - & - \\
\hline & $\geq 65$ & $174(59.0)$ & $35(20.1)$ & & - & - & - & $45(25.9)$ & & - & - & - \\
\hline \multirow{3}{*}{$\begin{array}{l}\text { Primary tumor } \\
(\mathrm{pT})\end{array}$} & pTa & $84(28.5)$ & $1(1.4)$ & $<0.0001^{*}$ & 1 & - & $<0.0001^{*}$ & $4(4.8)$ & $<0.0001^{*}$ & 1 & - & $0.011^{*}$ \\
\hline & pT1 & $88(29.8)$ & $9(10.2)$ & & 3.817 & $1.748-8.333$ & & $23(26.1)$ & & 4.631 & $1.311-16.364$ & \\
\hline & pT2-pT4 & $123(41.7)$ & $42(34.1)$ & & 21.277 & $2.823-200.00$ & & 49 (39.8) & & 6.688 & $1.889-23.677$ & \\
\hline \multirow[t]{2}{*}{ Nodal metastasis } & Negative ( $\mathrm{pN} 0$ ) & $266(90.2)$ & $41(15.4)$ & $0.0002^{*}$ & 1 & - & 0.387 & $61(22.9)$ & $<0.0001^{*}$ & 1 & - & $0.037^{*}$ \\
\hline & $\begin{array}{l}\text { Positive } \\
\text { (pN1-pN3) }\end{array}$ & $29(9.8)$ & $11(37.9)$ & & 1.364 & $0.675-2.758$ & & $15(51.7)$ & & 1.939 & $1.042-3.607$ & \\
\hline \multirow[t]{2}{*}{ Histological grade } & Low grade & $56(19.0)$ & $2(3.6)$ & $0.0013^{*}$ & 1 & - & 0.889 & $5(8.9)$ & $0.0007^{*}$ & 1 & - & 0.711 \\
\hline & High grade & $239(81.0)$ & $50(20.9)$ & & 0.895 & $0.188-4.266$ & & $71(29.7)$ & & 0.809 & $0.264-2.481$ & \\
\hline \multirow[t]{2}{*}{ Vascular invasion } & Absent & $246(83.4)$ & $37(15.0)$ & $0.0024^{*}$ & 1 & - & 0.185 & $54(22.0)$ & $0.0001^{*}$ & 1 & - & 0.835 \\
\hline & Present & 49 (16.6) & 15 (30.6) & & 0.629 & $0.317-1.249$ & & $22(44.9)$ & & 1.067 & $0.580-1.964$ & \\
\hline \multirow[t]{2}{*}{ Perineural invasion } & Absent & $275(93.2)$ & $44(16.0)$ & $0.0001^{*}$ & 1 & - & 0.131 & $66(24.0)$ & $0.0007^{*}$ & 1 & - & 0.347 \\
\hline & Present & $20(6.8)$ & $8(40.0)$ & & 1.908 & $0.824-4.420$ & & $10(50.0)$ & & 1.429 & $0.679-3.009$ & \\
\hline
\end{tabular}




\begin{tabular}{|c|c|c|c|c|c|c|c|c|c|c|c|c|}
\hline \multirow[t]{3}{*}{ Parameter } & \multirow[t]{3}{*}{ Category } & \multirow{3}{*}{$\begin{array}{l}\text { Case No. } \\
(\%)\end{array}$} & \multicolumn{5}{|c|}{ Disease-specific Survival } & \multicolumn{5}{|c|}{ Metastasis-free Survival } \\
\hline & & & \multicolumn{2}{|c|}{ Univariate analysis } & \multicolumn{3}{|c|}{ Multivariate analysis } & \multicolumn{2}{|c|}{ Univariate analysis } & \multicolumn{3}{|c|}{ Multivariate analysis } \\
\hline & & & $\begin{array}{l}\text { No. of } \\
\text { event (\%) }\end{array}$ & p-value & R.R. & 95\% C.I. & p-value & $\begin{array}{l}\text { No. of } \\
\text { event }(\%)\end{array}$ & p-value & R.R. & 95\% C.I. & p-value \\
\hline \multirow{2}{*}{$\begin{array}{l}\text { Mitotic rate (per } 10 \\
\text { high power fields) }\end{array}$} & $<10$ & 139 (47.1) & $12(8.6)$ & $<0.0001^{*}$ & 1 & - & $0.011^{*}$ & $23(16.5)$ & $<0.0001^{*}$ & 1 & - & $0.019^{*}$ \\
\hline & $>=10$ & $156(52.9)$ & $40(25.6)$ & & 2.409 & $1.219-4.761$ & & $53(34.0)$ & & 1.871 & $1.109-3.156$ & \\
\hline \multirow[t]{2}{*}{ NDN expression } & Low & $147(49.8)$ & $10(6.8)$ & $<0.0001^{*}$ & 1 & - & $0.012^{*}$ & $21(14.3)$ & $<0.0001^{*}$ & 1 & - & $0.021^{*}$ \\
\hline & High & $148(50.2)$ & $42(28.4)$ & & 2.477 & $1.220-5.028$ & & $55(37.2)$ & & 1.852 & $1.098-3.123$ & \\
\hline
\end{tabular}

* Statistically significant.
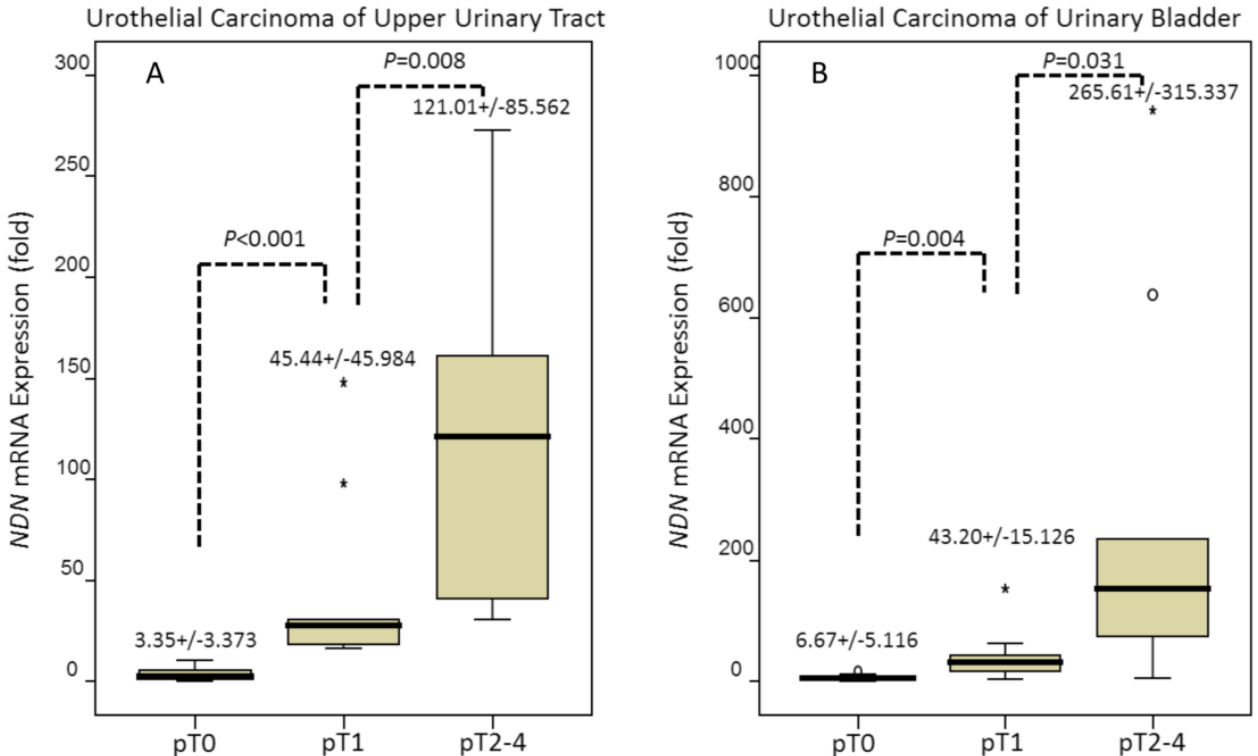

Figure 2. Quantitative real-time PCR (qPCR) analysis showed that NDN mRNA expression was significantly increased stepwise in both urothelial carcinomas of the upper urinary tract (left panel) and urinary bladder (right panel) along with more advanced primary pT status, from PTa to pTI and pT1 to pT2-4 (all P<0.05).
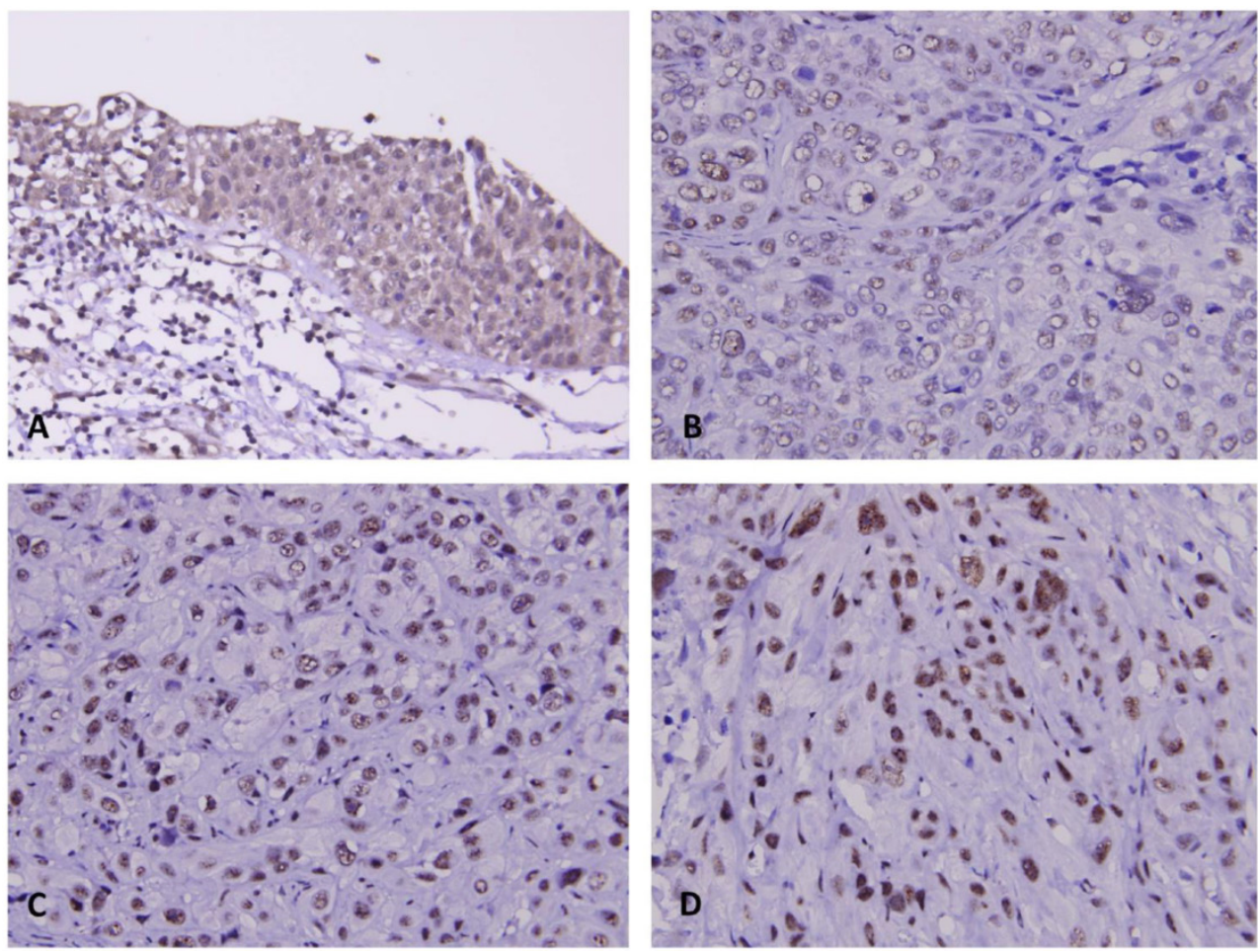

Figure 3. NDN immunostaining on representative sections revealed stepwise increase of NDN expression from non-tumoral urothelium (A), non-invasive (B), superficially infiltrating (PTI) (C) and deeply infiltrating (PT2-4) urothelial carcinoma (D). 

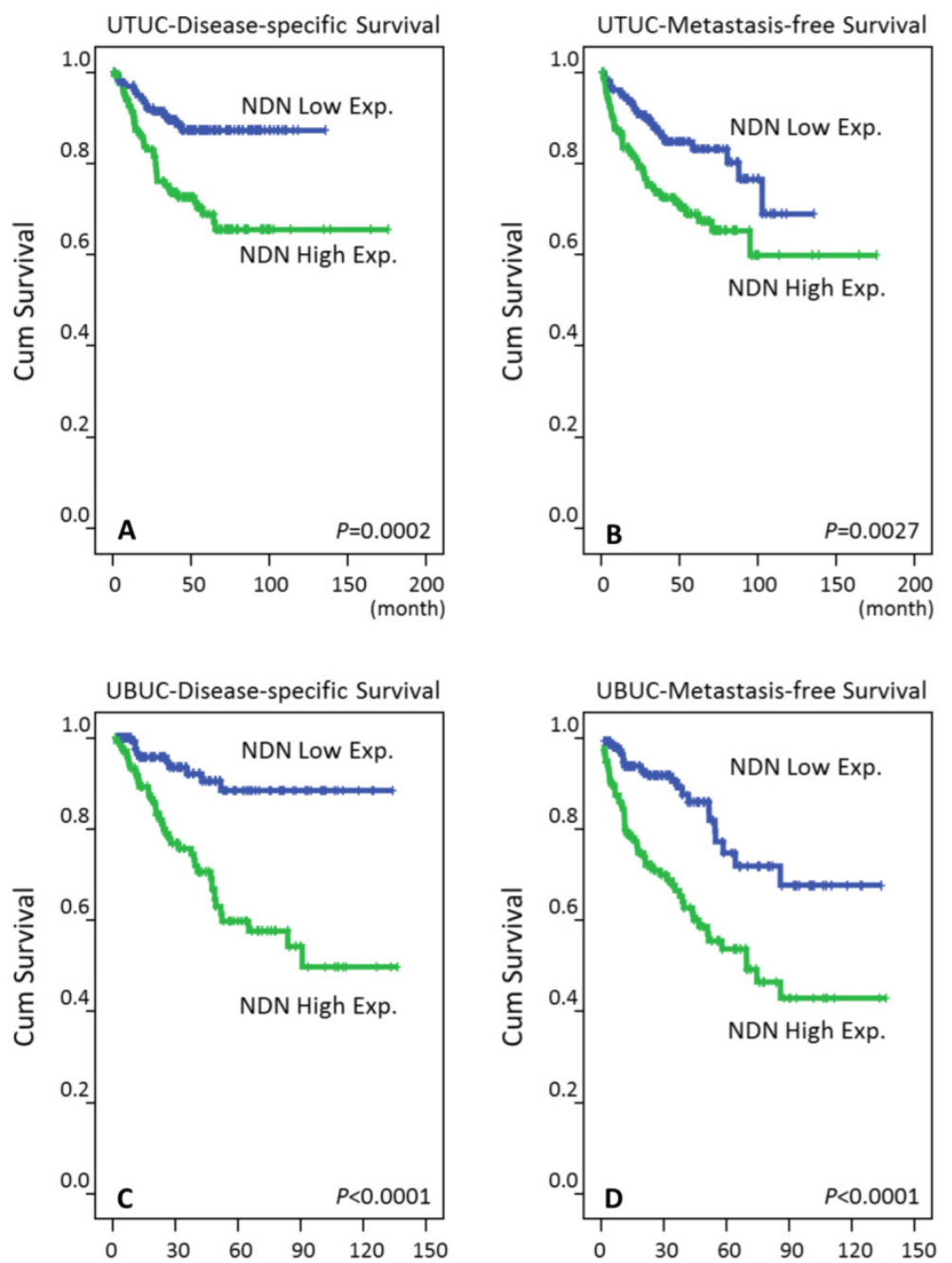

Figure 4. Kaplan-Meier plots disclosed the predictive value of NDN immunoreactivity for disease-specific survival (DSS) and metastasis-free survival (MeFS) in both groups of UTUC (A and B for DSS and MeFS, respecitvely) and UBUC (C and $\mathbf{D}$ for DSS and MeFS, respectively) (all $P<0.005$ ).

\section{Discussion}

Urothelial carcinoma is prevalent worldwide and has high recurrence rates [27]. Pathological staging is still the most decisive prognosticator of outcomes for bladder cancer, where five-year survival rates are approximately $60 \%$ to $85 \%$ for T2 bladder cancers after cystectomy, but decrease rapidly to $40 \%$ to $60 \%$ for T3 tumors [28]. In spite of the introduction of cisplatin-based combination chemotherapy, the prognosis is still poor for advanced stage bladder cancers; so far bladder cancer is ranked as the thirteenth most common cause of cancer death in the world (GLOBOCAN 2012 http://globocan.iarc.fr). Therefore, developing more potent therapeutic regimens is of crucial importance for high-risk patients.

Every cancer has ten hallmarks: sustaining proliferative signaling, evading growth suppressors, avoiding immune destruction, enabling replicative immortality, tumor-promoting inflammation, activating invasion and metastasis, inducing angiogene- sis, genome instability and mutation, resisting cell death, and deregulating cellular energetics [29]. Among these characteristics, sustaining proliferative signaling, that is, cell growth dysregulation, serves as the first step of oncogenesis.

The maternally imprinted gene, $N D N$, is associated with Prader-Willi syndrome [30]. Necdin, encoded by the NDN gene, is a 325 -amino acid protein belonging to the MAGE family $[18,19]$. The function of Necdin protein is similar to $\mathrm{Rb}$, which has been shown to interact with viral oncogenes such as simian virus 40 (SV40) large $\mathrm{T}$ antigen and adenovirus E1A, as well as E2F1 and p53 [31, 32]. Nevertheless, Necdin also bears oncogenic properties. Necdin's inhibitory effect on p53-mediated growth arrest and suppressive impact on p53-dependent apoptosis have also been demonstrated to be oncogenic functions [33, 34]. In line with this, there have been divergent results for Necdin expression in different cancers of each study. The scarcity of Necdin expression in brain tumor cell lines [35], as well as its decreased expression in mel- 
anomas [36] and bladder cancer cell lines and tumors [21] suggest NDN may be a tumor suppressor gene. Conversely, upregulation and loss of imprinting of Necdin in pancreatic cancers have been demonstrated by more recent studies $[37,38]$. The paradoxical results of experiments designed to recognize the role of Necdin in oncogenesis indicate that it has complex functions, which may be due to different microenvironments and cellular contexts [34]. Our current investigation proves the possible oncogenic role of NDN in UCs, which is not consistent with a previous study that found NDN was downregulated in bladder cancer cell lines and tumors [21]. A study by Chapman, et al. [21] first observed that NDN was induced to be downregulated in normal human urothelial cells transducted by hTERT, the catalytic subunit of telomerase. After that, the authors found NDN transcripts were downregulated in 26 of 28 (92.9\%) bladder cancer cell lines and 35 of $58(60 \%)$ bladder cancer tumors. However, the researchers neither correlated the NDN transcription levels with clinicopathological significance nor analyzed their association with survival. In addition, to the best of our knowledge, the current investigation is the first to inspect the relationship between NDN expression of both mRNA and protein levels, along with clinical outcomes in UTUC.

\section{Conclusion}

In sum, our work demonstrates that NDN gene and NDN protein (a.k.a. Necdin) plays an influential role in tumor progression of UCs. High expression of Necdin in both UTUC and UBUC is associated with worse clinicopathological parameters. Overexpression of Necdin is also an independent prognosticator of inferior DSS and MeFS in both groups. Further research to elucidate the details of the biological role of the NDN gene and Necdin in carcinogenesis of UC is essential for exploring the potential of NDN-targeted therapy for UCs, as we illustrated the hopeful targets for new strategies for UC therapy lately [39-41].

\section{Supplementary Material}

Supplementary methods and Figure S1.

http://www.jcancer.org/v07p0304s1.pdf

\section{Acknowledgements}

The authors are grateful to the BioBank at Chi Mei Medical Center for providing tumor samples.

\section{Grant Support}

This work was sponsored by E-DA Hospital (EDAHP104014 to I-W Chang), Taiwan Ministry of Science and Technology (NSC99-2320-B-384-001-MY2 and NSC101-2320-B-384 -001 -MY3), Ministry of Health and Welfare (DOH102-TD-M-111-102001 and
MOHW104- TDU-B-212-124-003, from Health and Welfare surcharge on tobacco products, to C-F Li and W-J Wu) and Kaohsiung Medical University (KMU-TP103G01, KMU-TP103G00, KMU-TP103G04, KMU-TP103G05) This study was also supported by grants from Kaohsiung Medical University "Aim for the Top Universities (KMU-TP103E19).

\section{Competing Interests}

The authors have declared that no competing interest exists.

\section{References}

1. Eble JN, Sauter G, Epstein JI, Sesterhenn IA. World Health Organization Classification of Tumours. Pathology and Genetics of Tumours of the Urinary System and Male Genital Organs. Lyon, Fance: International Agency for Research on Cancer (IARC) press; 2004.

2. Siegel R, Ma J, Zou Z, Jemal A. Cancer statistics, 2014. CA Cancer J Clin. 2014;64:9-29.

3. Raman JD, Messer J, Sielatycki JA, Hollenbeak CS. Incidence and survival of patients with carcinoma of the ureter and renal pelvis in the USA, 1973-2005. BJU Int. 2011;107:1059-64.

4. Chou $\mathrm{YH}$, Huang $\mathrm{CH}$. Unusual clinical presentation of upper urothelial carcinoma in Taiwan. Cancer. 1999;85:1342-4

5. Yang MH, Chen KK, Yen CC, et al. Unusually high incidence of upper urinary tract urothelial carcinoma in Taiwan. Urology. 2002;59:681-7.

6. Tan LB, Chen KT, Guo HR. Clinical and epidemiological features of patients with genitourinary tract tumour in a blackfoot disease endemic area of Taiwan. BJU Int. 2008;102:48-54

7. McLaughlin JK, Silverman DT, Hsing AW, et al. Cigarette smoking and cancers of the renal pelvis and ureter. Cancer Res. 1992;52:254-7.

8. Pommer W, Bronder E, Klimpel A, Helmert U, Greiser E, Molzahn M. Urothelial cancer at different tumour sites: role of smoking and habitual intake of analgesics and laxatives. Results of the Berlin Urothelial Cancer Study. Nephrol Dial Transplant. 1999;14:2892-7.

9. Shinka T, Miyai M, Sawada Y, Inagaki T, Okawa T. Factors affecting the occurrence of urothelial tumors in dye workers exposed to aromatic amines. Int J Urol. 1995;2:243-8.

10. Stewart JH, Hobbs JB, McCredie MR. Morphologic evidence that analgesic-induced kidney pathology contributes to the progression of tumors of the renal pelvis. Cancer. 1999;86:1576-82.

11. Debelle FD, Vanherweghem JL, Nortier JL. Aristolochic acid nephropathy: a worldwide problem. Kidney Int. 2008;74:158-69.

12. Laing C, Hamour S, Sheaff M, Miller R, Woolfson R. Chinese herbal uropathy and nephropathy. Lancet. 2006;368:338.

13. Dragicevic D, Djokic M, Pekmezovic T, et al. Survival of patients with transitional cell carcinoma of the ureter and renal pelvis in Balkan endemic nephropathy and non-endemic areas of Serbia. BJU Int. 2007;99:1357-62.

14. Catto JW, Yates DR, Rehman I, et al. Behavior of urothelial carcinoma with respect to anatomical location. J Urol. 2007;177:1715-20.

15. Zhang Z, Furge KA, Yang XJ, Teh BT, Hansel DE. Comparative gene expression profiling analysis of urothelial carcinoma of the renal pelvis and bladder. BMC Med Genomics. 2010;3:58.

16. Croce CM. Oncogenes and cancer. N Engl J Med. 2008;358:502-11.

17. Hanahan D, Weinberg RA. The hallmarks of cancer. Cell. 2000;100:57-70.

18. Barker PA, Salehi A. The MAGE proteins: emerging roles in cell cycle progression, apoptosis, and neurogenetic disease. J Neurosci Res. 2002;67:705-12.

19. Maruyama K, Usami M, Aizawa T, Yoshikawa K. A novel brain-specific mRNA encoding nuclear protein (necdin) expressed in neurally differentiated embryonal carcinoma cells. Biochem Biophys Res Commun. 1991;178:291-6.

20. Hayashi Y, Matsuyama K, Takagi K, Sugiura H, Yoshikawa K. Arrest of cell growth by necdin, a nuclear protein expressed in postmitotic neurons. Biochem Biophys Res Commun. 1995·213:317-24.

21. Chapman EJ, Kelly G, Knowles MA. Genes involved in differentiation, stem cell renewal, and tumorigenesis are modulated in telomerase-immortalized human urothelial cells. Mol Cancer Res. 2008;6:1154-68.

22. Huang WW, Huang HY, Liao AC, et al. Primary urothelial carcinoma of the upper tract: important clinicopathological factors predicting bladder recurrence after surgical resection. Pathol Int. 2009;59:642-9.

23. Wu LC, Chen LT, Tsai YJ, et al. Alpha-methylacyl coenzyme A racemase overexpression in gallbladder carcinoma confers an independent prognostic indicator. J Clin Pathol. 2012;65:309-14.

24. Budwit-Novotny DA, McCarty KS, Cox EB, et al Immunohistochemical analyses of estrogen receptor in endometrial adenocarcinoma using a monoclonal antibody. Cancer Res. 1986;46:5419-25. 
25. McClelland RA, Finlay P, Walker KJ, et al. Automated quantitation of immunocytochemically localized estrogen receptors in human breast cancer. Cancer Res. 1990;50:3545-50.

26. Liang PI, Wang $\mathrm{YH}, \mathrm{Wu}$ TF, et al. IGFBP-5 overexpression as a poor prognostic factor in patients with urothelial carcinomas of upper urinary tracts and urinary bladder. J Clin Pathol. 2013;66:573-82.

27. Rodriguez-Alonso A, Pita-Fernandez S, Gonzalez-Carrero J, Nogueira-March JL. Multivariate analysis of survival, recurrence, progression and development of mestastasis in T1 and T2a transitional cell bladder carcinoma. Cancer. 2002;94:1677-84

28. Townsend CM JR, Evers BM, Mattox KL. Sabiston Textbook of Surgery: The Biological Basis of Modern Surgical Practice. 16th ed. Philadelphia, USA: Saunders; 2002.

29. Hanahan D, Weinberg RA. Hallmarks of cancer: the next generation. Cell. 2011;144:646-74.

30. Jay P, Rougeulle C, Massacrier A, et al. The human necdin gene, NDN, is maternally imprinted and located in the Prader-Willi syndrome chromosomal region. Nat Genet. 1997;17:357-61.

31. Taniura H, Matsumoto K, Yoshikawa K. Physical and functional interactions of neuronal growth suppressor necdin with p53. J Biol Chem. 1999;274:16242-8.

32. Taniura H, Taniguchi N, Hara M, Yoshikawa K. Necdin, a postmitotic neuron-specific growth suppressor, interacts with viral transforming proteins and cellular transcription factor E2F1. J Biol Chem. 1998;273:720-8.

33. Hasegawa K, Yoshikawa K. Necdin regulates p53 acetylation via Sirtuin1 to modulate DNA damage response in cortical neurons. J Neurosci. 2008;28:8772-84

34. Lafontaine J, Rodier F, Ouellet V, Mes-Masson AM. Necdin, a p53-target gene, is an inhibitor of p53-mediated growth arrest. PLoS One. 2012;7:e31916.

35. Aizawa T, Maruyama K, Kondo H, Yoshikawa K. Expression of necdin, an embryonal carcinoma-derived nuclear protein, in developing mouse brain. Brain Res Dev Brain Res. 1992;68:265-74.

36. Hoek K, Rimm DL, Williams KR, et al. Expression profiling reveals novel pathways in the transformation of melanocytes to melanomas. Cancer Res. 2004;64:5270-82.

37. Tan AC, Jimeno A, Lin SH, et al. Characterizing DNA methylation patterns in pancreatic cancer genome. Mol Oncol. 2009;3:425-38.

38. Wang L, Liu HL, Li Y, Yuan P. Proteomic analysis of pancreatic intraepithelial neoplasia and pancreatic carcinoma in rat models. World J Gastroenterol. 2011;17:1434-41.

39. Chang IW, Liang PI, Li CC, et al. HAS3 underexpression as an indicator of poor prognosis in patients with urothelial carcinoma of the upper urinary tract and urinary bladder. Tumour Biol. 2015;36:5441-50.

40. Chang IW, Lin VC, He HL, et al. CDCA5 overexpression is an indicator of poor prognosis in patients with urothelial carcinomas of the upper urinary tract and urinary bladder. Am J Transl Res. 2015;7:710-22.

41. $\mathrm{Li} \mathrm{CF}, \mathrm{Wu} \mathrm{WJ}, \mathrm{Wu} \mathrm{WR}$ et al. The cAMP responsive element binding protein 1 transactivates epithelial membrane protein 2, a potential tumor suppressor in the urinary bladder urothelial carcinoma. Oncotarget 2015;6:9220-39. 